\title{
Brief analysis on Econometrics of Domestic Tourism Income
}

\author{
Zhiwei Shao \\ Xi'an Eurasia University, Xi'an, Shaanxi, 710065, China
}

Keywords: Domestic tourism income, Influence factor, Model specification, Empirical analysis, Verification.

\begin{abstract}
At present, with the rapid social and economic development in China and the increase of people's living standard, all the people have basically entered the "era of travel", which has greatly promoted the vigorous development of the domestic tourism industry. In order to rationally optimize the economic benefits of the tourism industry and realize intelligent "era of travel", it is necessary to integrate domestic tourism revenues with the theory and practice of econometrics for fine analysis and calculation, and comprehensively measure the integrated indicators of national tourism industry development. In view of this, this paper has mainly analyzed the related factors and model specifications that influence the domestic tourism income, and carried out a series of empirical analysis and correlation tests by combining econometrics theory.
\end{abstract}

\section{Introduction}

Tourism income is a major source of revenues from China's national economic entities. However, the current scientific researches on it are relatively shallow without effectively combining qualitative and quantitative processes. Faced with the development status of thousands of times the tourism income increase since the reform and opening up, this article thinks it is necessary to empirically analyze the economic income of domestic tourism based on econometrics, and study the practical significance of tourism industry development on China's economic development.

\section{Brief analysis on the development status of domestic tourism industry}

Currently, China has entered the significant transition period of socialist market economy. The economy has developed rapidly and people's living standard has improved. As the world's second largest economy, China has made progress in all aspects. The flourishing development of the tourism industry is indicating the fact that the people's living standards are continuously improving, and the enjoy type consumption in people's life is more and more apparent. Tourism as the main leisure mode of national life has developed rapidly. China has increased the income from 7 billion yuan since the reform and opening up (1980) to the current 4,049 billion yuan (2017). The development speed is amazing. We can say that tourism industry as a part of the national economic development system has comprehensively improved national economic development rate. It has even played a role in promoting optimization and adjustment of the national economic structure, and realized the optimization and upgrading of peripheral tourism industry structure on a large scale. It has particularly solved the current difficult employment problems in Chinese society. Therefore, the development of the national tourism industry in China is showing a very obvious multiplier effect. It has comprehensive promoted the sustainable, healthy and stable development of the national economy. Study on economic income of the domestic tourism industry is also of important realistic value for the healthy and sustainable development of the national economy. 


\section{Analysis on the model specifications and influencing factors based on domestic tourism income}

\subsection{Analysis on influencing factors of domestic tourism income}

While analyzing multiple influencing factors of domestic tourism income, model indicators should be set for each influencing factor at the same time so that they can be integrated into the architecture model afterwards. In this paper, following five factors influencing domestic tourism income are indicated.

Firstly, the number of domestic tourists should be mentioned and set as X1, which is a direct key influencing the income of the domestic tourism economy. Thus it should be firstly analyzed. Combining the contents of economic theory with the reality of China's tourism market, consumer group in the tourism industry has been on the rise since China's reform and opening up, and consumer groups have kept gathering on a large scale. This is also the reason why the tourism industry can thrive and tourism income can increase. The increase in the number of domestic tourists has to a certain extent promoted the sustainable and healthy development of the domestic economy. Therefore, the number of domestic tourists X1 can be used as a major explanatory variable in model building.

Secondly, gross domestic product GDP is set as X2, which is the main indicator of China's national economic accounting, as well as the core indicator of the rapid development of social economy. The continuously increasing GDP will shows a good prospect of the national economic development, which will make for richer livelihood of people and more desire for spiritual satisfaction on the basis of satisfying material needs. Tourism is the main object that can stimulate people's life and meet their spiritual needs. Therefore, to pursue the higher spiritual life enjoyment, many people choose to travel, which greatly stimulates the overall rise of GDP. Thus GDP is used as the second explanatory variable.

The third one is per capita spending on domestic travel which is set as X3. First of all, it is necessary to make clear that the per capita spending on domestic tourism is positively related to tourism income. The per capita spending on tourism is subjectively reflecting the national's ability to pay. The stronger ability to pay, the higher the expenditures on tourism. At present, domestic tourism is presenting the development status of high-paying ability. Spending on tourism has been rising year by year. Here, the per capita tourism expenditure in China can be further subdivided into two major items: per capita spending on domestic travel of urban residents and per capita spending on domestic travel of rural residents. However, in this study, the possible multi-collinearity problem between the two or more factors should be avoided in this paper, and thus per capita spending on domestic travel $\mathrm{X} 3$ is set as the main explanatory variable.

The fourth one is the road mileage, which is set as X4. The road mileage is closely related to tourism development as traffic is the main route to convey the relevant elements of tourism. The diverse and convenient mode of transportation at present can satisfy people's various travel requirements. This provides unlimited possibilities for tourists to travel. With the continuous development of the national economy, more people prefer to free and leisure self-driving tour. So road mileage will be more obvious, which should be set as a major factor in domestic tourism income variables by adding and referring to the model for analysis.

\subsection{Model specifications and analysis}

To build the explanatory variable model by combining with the above-mentioned influencing factors, it is necessary to firstly analyze four major variables $\mathrm{X} 1 \sim \mathrm{X} 4$, and compare these four explanatory variables with other factors to form a positive correlation relationship between them. The economic model of domestic tourism income based on econometrics is as follows:

$$
Y=\beta+\beta 1 * X 1+\beta 2 * X 2+\beta 3 * X 3+\beta 4 * X 4+u
$$


Through calculating based on the above economic model by substituting into the data of domestic tourism economic income over the past 10 years, accurate data of domestic tourism income over years can be obtained to know the results of various explanatory variables presented in domestic tourism economic income from different aspects. In the model, the regression coefficient $\beta$ before each explanatory variable is expected to be greater than 0 . Then estimate the regression parameters based on the set model to prove the multicollinearity content in it. In other words, in the economic model, take the logarithm for $Y 、 X 1 、 X 2 、 X 3 、 X 4$ to generate symmetry data of $\ln Y \cdot \ln X 1 \cdot \ln X 2 \cdot \ln X 3 \cdot \ln X 4$ one by one. Substitute into actual data and add the above data $\mathrm{X} 1 \sim \mathrm{X} 4$ together to obtain the result $\ln Y$ to figure out the coefficient of determination and $F$ test value of the economic model. The final result shows that all estimated values of coefficients in the economic model are relatively significant.

Through the above-mentioned economic model specifications and analysis, it can be obtained that the goodness of fit of the economic model $R^{2}$ is 0.9999 , which means that the current domestic tourism income has a relatively high interpretation degree of $99.99 \%$, and the model has excellent fitting to the sample.

In $F$ test, combined with a given level of significance $\alpha=0.05$ or less, its $F$ test value can be obtained, and $P=0.000000$ can be obtained, which means that $F$ test is also significantly smaller than $\alpha=0.05$ level, and the regression equation performs significantly. In short, the combination of the two major explanatory variables, the number of domestic tourists and the per capita spending on domestic tourism, will have significantly positive impact on the domestic tourism economic income, which is worthy of attention.

During $T$ test process, the regression coefficient $t$ of each explanatory variable test $P \leq 0.05$, which indicates that the each explanatory variable has significantly positive impact on domestic tourism economic income.

\subsection{Analysis of test results based on econometrics}

In the process of autocorrelation testing, it is necessary to set a significant level of domestic tourism income $\alpha=0.05$, and then analyze econometrics table $\mathrm{DW}$, combine with each explanatory

variable to obtain the test value $d_{L}$ and the upper limit value ${ }^{d_{U}}$, and combine the DW table to verify the model content that cannot be judged in explanatory variables to determine whether or not its $\mathrm{P}$ value is up to standard $(\mathrm{P}>0.05)$. Finally, substitute the data into the economic model $\ln Y$ to figure out the final DW value.

It can be found from above a series of model specifications and numerical solution process that the model basically explains the various explanatory variables in domestic tourism income. When the number of domestic tourists increases by $1 \%$, the domestic tourism income will increase by approximately $1.0047 \%$. When the per capita spending on domestic tourism increases by $1 \%$, the domestic tourism income will increase by approximately $0.9973 \%$. The model shows that each explanatory variable has a very large impact on domestic tourism revenue. Therefore, to effectively promote the rapid growth of domestic tourism, it is necessary to accelerate the development process of the domestic tourism industry, and take the urban residents' tourism expenditure as the important influencing factor to promote tourism income increase for analysis and judgement so as to obtain better analytical results [2].

\section{Feasible proposals for domestic tourism income increase}

It can be seen from above a series of scientific analysis that the global tourism industry apart from China is showing a strong momentum, which has effectively promoted the national economic development with great potential. In this process, the increasingly improvement of national economic development has also affected the various explanatory variables mentioned in the paper. They have become the core elements to promote the development of the national tourism industry and laid the foundation for the national economy. This also shows that a close economic equilibrium 
interdependent relationship has been established between the development of the national economy and the tourism industry, and as one falls another rises. Under the background of China's new normal economy, the vigorous development of the tourism industry has increasingly become an important driving force to promote national economic growth. Therefore, it is necessary to combine various explanatory variables with national policies based on this together with the quantitative qualitative analysis explained above to propose a series of feasible suggestions for the effective growth of the national tourism income in the future, and to provide valuable referential path for the substantial development of the national tourism industry.

\subsection{Feasibility analysis of domestic tourism income increase based on explanatory variables}

First of all, we must consider and analyze the growth feasibility of each explanatory variable for the domestic tourism income. The correlations between the selection of various explanatory variables and the economic model specification should be considered. They are the most significant core factors affecting domestic tourism income. They are positively positive correlated to domestic tourism revenues, and therefore. So following two suggestions are provided to improve domestic tourism income.

First of all, the number of domestic tourists should be considered. In order to attract a large number of tourists, tourism industry companies must reorganize and analyze the tourism target markets for technical subdivision. For example, consider different levels of tourist resources design and different types of tourism consumer classification according to local conditions and tourism resources so as to establish targeted layered product line. Make great efforts to develop and innovate tourism types in the tourism resources region. For example, the popular MICE tourism, ecological natural tourism, cultural tourism can effectively stimulate tourists' participation and consumption awareness, establish tourism consumption, and increase local tourism income.

Secondly, per capita spending on domestic tourism should be considered, which is the most direct factor influencing consumer spending. Fundamentally speaking, it is necessary to increase the disposable income of the urban population in China. The more disposable income, the stronger travel intention of the urban residents. Therefore, it is necessary to vigorously publicize the educational content of disposable income, effectively eliminate consumers' expected fear and pessimism psychology, and constantly strengthen the tourists' expected consumption confidence, and satisfy their travel consumption needs by enriching diverse tourism resources. Hence, from the perspective of tourism resources and production products, local tourism companies must pay attention to the differentiation and classification of tourism product prices and contents, so as to satisfy different consumer groups with different levels of consumption and culture. For example, ancient village and ancient courtyard resorts, eco-tourism can strengthen people's willingness to travel to a certain extent, attract more tourists to consume. Effective innovation of tourism resources can also promote the sustainable and vigorous development of China's tourism industry.

\subsection{Feasibility analysis of domestic tourism income increase based on government policies}

To encourage tourists' consumption and promote domestic tourism income, the government must also actively introduce encouraging policies to stimulate domestic demands and increase income for local residents. In this paper, the author thinks the rapid development of the tourism industry can be achieved by satisfying tourists' spiritual civilization pursuit which can change the traditional concept of social consumption and encourage tourists to invest more tourism consumption into the spiritual enjoyment. Therefore, the government must expand the tourism regional center from the cities and townships to the rural areas, actively give play to industrial concentration of the urban population and the rural population, on the one hand, expand tourism regional size; on the other hand, re-position the tourist service center and excavate the huge potential of tourism industry. Furthermore, the government must also develop more cultural tourism characteristic cultural market in line with cultural resources, particularly cultivate high-end cultural tourism market, attract domestic and foreign tourists' consumption, introduce more foreign capital, and guarantee that the domestic tourism income can increase steadily [3]. 


\section{Conclusion}

By combining with scientific analysis and policy advancement, this paper mainly analyzed domestic tourism income growth from the perspective of econometrics with the hope that that this economic model can fit China's current domestic tourism income situation. And this paper has also proposed a series of feasible development strategies for the future development of China's tourism industry to continuously maintain the vigorous development of the tourism industry.

\section{Acknowledgement}

This research was financially supported by the Ministry of Education 2017 Yueqian Technology industry-academy cooperation education project, Project No.: 201702071032.

\section{References}

[1] Wang Yawen. Econometrics research on domestic tourism income, Journal of Chifeng College (Natural Science Edition), 2017(23):134-136.

[2] Zhao Ruyue. Studies on domestic tourism income in the new normal-based on econometric model, Business, 2015(22):254-254,242.

[3] He jiangying, Econometrics analysis influencing Chinese domestic tourism income, Shangqing, 2014(18):23. 